\title{
Season to taste
}

There is a temptation to share recipes with colleagues and friends. This is all very well but beware: there are certain rules that you should follow. Stephen Hancocks heads for the Vital oven.

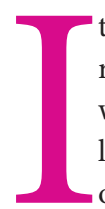

t starts innocently enough. A chance remark, a mention of a menu from the weekend, a taster of a team member's lunch and there will be an immediate offer from a willing party to give you the recipe. It might be one with a family history, passed down from mother to daughter or grandparent to aunt, that sort of thing, and may even be produced in its original form as a crumpled piece of ingredient-stained paper or an aged cardboard box lid scrawled with curious characters in an otherwise forgotten central European dialect which fortunately the current custodian can still recall. Alternatively it might be 'one of Delia's', or 'a Nigella special', a 'Nigel's top tip' yet with a slight twist, a personalisation brought about through countless times of preparing it and discovering that just that extra two ounces of ginger makes all the difference.

You happily, and politely, say thank you and wait for the carefully written one side of A4 to arrive, or possibly the email or in the case of a cheese, chutney and coleslaw club sandwich, a tweet. Very grand cooks will type it out for you but whatever form it arrives in here's the first warning: check the sequence of preparation before embarking on making it, whatever 'it' is. The reason is that with recipes with which we are intimately familiar they can be executed so blindly that essential steps are either missed out completely, or placed in the wrong order. So you get down to the moment of having beaten the eggs, get the oven to $180^{\circ} \mathrm{C}$, greased the tin and then the instructions floor you by saying 'now add the beef which has been marinated for two days in the honey-mustard sauce (see separate sheet)'. You haven't, of course, even made the sauce and the guests are due in something less than 48 hours.

However, let's be optimistic. You gladly accept the recipe for what it is and hurry back to the kitchen range to try it out. Actually it doesn't turn out halfbad. To be honest, as a first attempt it has risen,

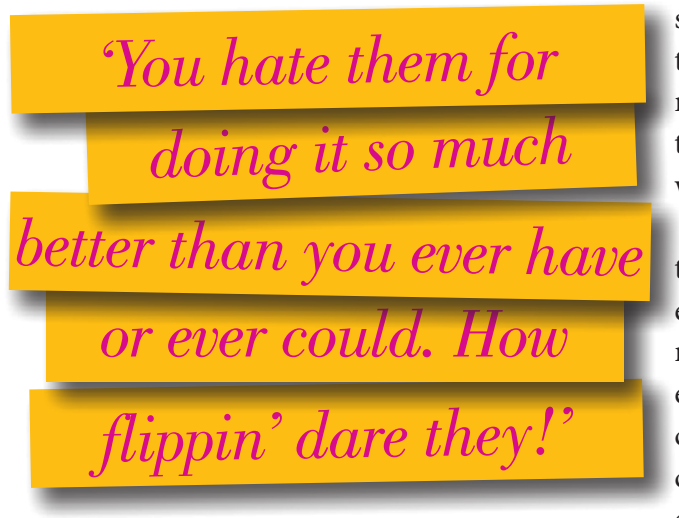

fallen, gone brown, stayed white, crumpled, smoothed out, peaked, dipped, firmed, softened or melted more or less as it should. To put not too fine a point chuffed. In fact so proud of your premier attempt that you decide to present a on it, you're a bit

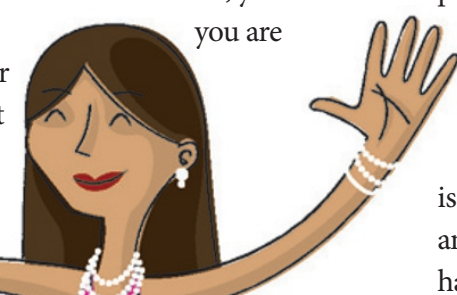
prowess, presents you with a dish of your the recipe. Agggh! Stop. Warning claxon! Never, never, under any circumstances be tempted to take the offering back to the source: calamity will ensue.

Why? Okay, here's the thing (actually all good television cooks say that now - practise it for effect) here's the thing ... imagine the roles are reversed. It is you who have been kind hearted enough to share a treasured culinary secret, carefully copied it out and paid attention to the correct sequence, exact measures of ingredients, cooking temperatures, everything in apple pie (or chicken stroganoff) order. The recipient, thinking that they are doing you a huge favour and paying homage to your gastronomic special creation. One of three things will

happen. It will taste dreadful - you hate them for defiling the memory of your dead grandparents in the Urals; it tastes fantastic, it is mouth watering and succulent, it is splendid and gorgeous and totally, totally delicious - you hate them for doing it so much better than you ever have or ever could. How flippin' dare they! Thirdly: it is exactly like yours turns out to be - you hate them for being a copycat, daring to emulate your skills and not even having the imagination to vary it by a teaspoon of this or a drizzle of that. Any which way it is the end of a happy working relationship.

But be warned, there is a greater danger yet, a crime so ghastly that it risks tearing the practice asunder on the very next Monday morning. You invite round to dinner the purveyor of the recipe but don't tell them until the lid comes off the casserole, the top off the meat plate that you're surprising them with their own dish! One of four things will happen: any of the above plus, if they had REALLY wanted to eat their own food they'd have stayed at home. Exchange recipes by all means just never share the results! 